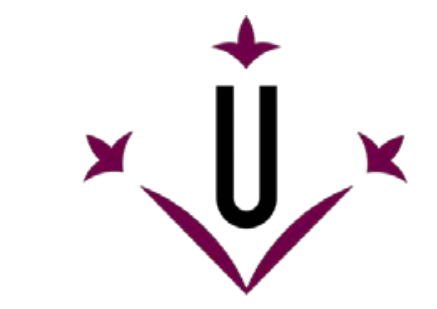

Universitat de Lleida

Document downloaded from:

http://hdl.handle.net/10459.1/62951

The final publication is available at:

https://doi.org/10.1002/jsfa.7343

\title{
Copyright
}

(c) Society of Chemical Industry, 2015 


\section{Conidia survival of Aspergillus section Nigri, Flavi and Circumdati under UV-A and UV-B radiation with cycling temperature/light regime}

Maria Esther García-Cela, Sonia Marín, Monica Reyes, Vicent Sanchis, Antonio J Ramos

* Correspondence to: Maria Esther García-Cela, Applied Mycology Unit, Food Technology Department, University of Lleida, UTPV-XaRTA, Agrotecnio Centre, Av. Rovira Roure 191, 25198 Lleida, Spain, E-mail: esthergcela@gmail.com

Applied Mycology Unit, Food Technology Department, University of Lleida, UTPV-XaRTA, Agrotecnio Centre, 25198, Lleida, Spain

Keywords: climate change; fungi; mycotoxins; pigments; A. carbonarius; A. tubingensis; A. flavus; A. parasiticus; A. westerdijkiae; A. ochraceus

\section{Abstract}

Bio-geographical differences in fungal infection distribution have been observed around the world, confirming that climatic conditions are decisive in colonization. This research is focused on the impact of ultraviolet radiation (UV) on Aspergillus species, based on the consideration that an increase in UV-B radiation may have large ecological effects.

Conidia of six mycotoxigenic Aspergillus species isolated from vineyards located in the northeast and south of Spain were incubated for 15 days under light/dark cycles and temperatures between 20 and $30^{\circ} \mathrm{C}$ per day. Additionally, $6 \mathrm{~h}$ of exposure to UV-A or UV-B radiation per day were included in the light exposure. UV irradiance used were $1.7 \pm 0.2 \mathrm{~mW}$ $\mathrm{cm}-2$ of UV-A (peak $365 \mathrm{~nm}$ ) and $0.10 \pm 0.2 \mathrm{~mW} \mathrm{~cm}-2$ of UV-B (peak $312 \mathrm{~nm}$ ). The intrinsic decrease in viability of conidia over time was accentuated when they were UV irradiated. UV-B radiation was more harmful.

Conidial sensitivity to UV light was marked in Aspergillus section Circumdati. Conidia pigmentation could be related to UV sensitivity. Different resistance was observed within species belonging to sections Flavi and Nigri. An increase in UV radiation could lead to a reduction in the Aspergillus spp. inoculum present in the field (vineyards, nuts, cereal crops). In addition, it could unbalance the spore species present in the field, leading to a higher predominance of dark-pigmented conidia.

\section{INTRODUCTION}

Aspergillus can contaminate agricultural products at different stages, including pre-harvest, harvest, storage, processing and handling. Aspergillus species have been isolated in field surveys from several commodities such as corn, rice, wheat, Brazil nuts, peanuts, pistachios, figs, grapes, onions, pepper, coffee and cocoa.1-12 Aspergillus species are divided into different morphological sections according to the different colours of their pigments. Aspergillus sections Nigri (black), Flavi (green) and Circumdati (yellow) are the most studied sections in this genus owing to their potential toxicity. Fungal infection of crops can result in food secondary rots, with the possible accumulation of mycotoxins. 13 Moreover, climatic 
conditions directly affect fungal infection and the subsequent mycotoxin contamination in foods and raw materials.

Recently, the Intergovernmental Panel on Climate Change (IPCC) published a Fifth Assessment Report (AR5), in which it was concluded that climate warming is 'unequivocal', and that it is likely that anthropomorphic greenhouse gas emissions contribute to current warming trends.14 The impact of climate change has been identified as an emerging issue for food and feed safety, 15 and its possible consequences on mycotoxin production in crops have been theorized by several research studies.15-20 Moreover, the World Meteorological Organization (WMO) has also highlighted that human emissions of chlorofluorocarbons (CFCs) and other chemicals have an important role in atmospheric changes by damaging the stratospheric ozone layer, which filters out harmful ultraviolet radiation (UV).21 UV radiation affects fungal spore germination, growth and sporulation, the effect depending on time exposure, UV wavelength and fungal species.22-27

The United Nations Environment Programme (UNEP) considered that increased UV-B radiation, interacting with other global change factors, may affect many of the important ecosystems processes and attributes, such as plant biomass production, plant consumption by herbivores including insects, disease incidence of plants and animals, changes in species abundance and composition and mineral nutrient cycling, with important implications for food security and food quality. 28,29

Although information concerning the effects of UV-B on fungi and bacteria is scarce, studies on microfungal communities in soils of extreme habitats, such as desert (very high solar radiation, drought, and extreme temperatures), suggest the dominance of dark-coloured microfungi with large multicelled conidia.30, 31 Likewise, the main airborne fungal species identified at a coastal station after exposure to solar radiation were predominantly Aspergillus niger, Alternaria alternata, Cladosporium cladosporoides and Arthrinium phaerosporum.32 Therefore, Aspergillus species could prevail over other species under high-UV-radiation environments. Moreover, species of the genus Aspergillus (mainly A. fumigatus) and teleomorphic ascomycetes show a certain thermotolerance.30

The main goal of our investigation was to assess survival under UV radiation of conidia from six species belonging to the Aspergillus genus. The effects of isolate origin and pigmentation of conidia on resistance to UV light were also assessed.

\section{MATERIALS AND METHODS}

Isolates

Isolates from berries collected at harvesting time in two different Spanish wine-growing regions were used in this study (Table 1). The vineyards were located in Catalonia and Andalucia, which are located in the northeast and south of Spain, respectively. The climate in the vineyards sampled in the northeast is defined as cold steppe (BSk), while in the south it is temperate with dry or hot summer (Csa) according to the Köppen Climate Classification of the Iberian Peninsula Climate Atlas.33 A similar cropping system is used in both areas, except for irrigation, which is by the drip method in the case of the northern fields, whereas in the 
southern fields there was no irrigation. Isolation and identification of Aspergillus spp. have been detailed by García-Cela et al.34

Six species belonging to three aspergilli sections (two species each) were chosen for their mycotoxin production ability, and for the presence of such mycotoxins in food commodities such as grapes (ochratoxin A, from A. carbonarius), pistachio nuts (aflatoxins) and wheat (ochratoxin A, from several Aspergillus species belonging to sections Nigri and Circumdati). Thus one isolate each of $A$. carbonarius and $A$. tubingensis, $A$. flavus and $A$. parasiticus, and $A$. ochraceus and A. steynii, from sections Nigri, Flavi and Circumdati, respectively, were used.

\section{Experimental design}

For inocula preparation, different culture media were used for each species, simulating frequent commodities from which they are commonly isolated. Aspergillus sections Nigri, Flavi and Circumdati were inoculated on to synthetic nutrient medium (SNM),35 pistachio-based medium (PBM) and wheat-based medium (WBM), respectively. For the PBM and WBM preparation, $30 \mathrm{~g}$ pistachio or wheat were ground and boiled in $1 \mathrm{~L}$ distilled water for $30 \mathrm{~min}$. Subsequently, the extract was filtered with gauze and $15 \mathrm{~g}$ agar were added and the volume made up to $1 \mathrm{~L}$. After that, media were autoclaved for $15 \mathrm{~min}$ at $121^{\circ} \mathrm{C}$. Isolates were grown for 7 days at $25^{\circ} \mathrm{C}$ in the dark to enable significant sporulation. After this, spores were removed from Petri dishes and suspended in $80 \mathrm{~mL}$ sterile water containing $0.05 \%(\mathrm{w} / \mathrm{v})$ Tween 80 to reach a final concentration of 105 conidia $\mathrm{mL}-1$. Aliquots $(5 \mathrm{~mL})$ of conidial suspensions were filtered under vacuum on to individual sterile filter membranes (pore size $0.45 \mu \mathrm{m}, 25 \mathrm{~mm}$ diameter, cellulose acetate filter) (Sartorius Biolab Products, Göttingen, Germany). A total of 12 membranes for each isolate were used (six replicates for each treatment, irradiated and control). Membranes were enclosed in pairs in $5 \mathrm{~cm}$ diameter plastic Petri dishes and dried at $37^{\circ} \mathrm{C}$ in microbiology incubators overnight.36 Spores deposited on filter membranes were exposed to radiation and temperature cycles for 15 days, as described latter.

The strains were incubated under particular photoperiod and temperature conditions in order to simulate the conditions characteristic for the period of grape ripening in Spain (August). Photoperiod values were obtained from the National Spanish Geographic Institute (IGN), while temperatures were obtained from the Spanish Meteorological Association (AEMET). Daily light and temperature conditions for incubation are described in Fig. 1, following the methodology described in García-Cela et al.37

UV-irradiated and non-irradiated isolates were incubated in parallel under the same conditions in two cooled incubators (Memmert ICP-600, UK). Daylight was simulated with four cold-white fluorescent lights (standard illuminant D65, $6500 \mathrm{~K}$ ) located in the incubators. UV irradiation was generated with a Vilber Lourmat lamp VL-215.LM (Germany). The lamp consisted of two fluorescent tubes of $15 \mathrm{~W}$ each and a filter to minimize light interference. UV-A extends from 320 to $400 \mathrm{~nm}$ with an energy peak at $365 \mathrm{~nm}$ and UV-B runs from 280 to $370 \mathrm{~nm}$ with an energy peak at $312 \mathrm{~nm}$ (Fig. 2). Petri plates were placed at a distance of 8 and $32 \mathrm{~cm}$ from the UV-A and UV-B lamps, resulting in an irradiation of $1.7 \pm 0.2 \mathrm{~mW} \mathrm{~cm}-2$ and $0.10 \pm 0.2 \mathrm{~mW}$ $\mathrm{cm}-2$ for UV-A and UV-B, respectively. The irradiation was measured with a portable UV light meter (UVA-UVB PCE-UV34, PCE Iberica SL, Spain). Values of radiant energy were chosen 
according to annual values characteristic for the south of Spain, with a high sum of annual hours of sun.38 Annual values for UV-A ranged from 0.06 to $2.49 \mathrm{~mW} \mathrm{~cm}-2$, with a mean value of $1.17 \mathrm{~mW} \mathrm{~cm}-2$, while for UV-B they were from $<0.001$ to $0.23 \mathrm{~mW} \mathrm{~cm}-2$, with a mean value of $0.09 \mathrm{~mW} \mathrm{~cm}-2$. Considering the doses and exposure time, the daily accumulated UV-A and UV-B radiation in the experiments was 0.367 and $0.022 \mathrm{MJ} \mathrm{m}-2$, respectively. The mean daily accumulated annual UV-A radiation was $0.464 \mathrm{MJ} \mathrm{m-2}$ and, focusing on harvest months, values were $0.632 \mathrm{MJ} \mathrm{m}-2$ in August and $0.539 \mathrm{MJ} \mathrm{m}-2$ in September. The UV-B mean daily accumulated annual value was $0.035 \mathrm{MJ} \mathrm{m}-2$, whereas in August it was $0.050 \mathrm{MJ} \mathrm{m-2}$. Direct UV doses used in the study were higher than the global (direct + diffuse) UV mean values recorded in the south of Spain, but daily accumulated irradiation was lower due to the lower number of hours of exposure.

Each 5 days (5th, 10th and 15th day) conidia were dislodged from two control and two irradiated membranes into $100 \mathrm{~mL}$ sterile peptone $(0.1 \% \mathrm{w} / \mathrm{v})$ solution using a stomacher. Subsequently, serial dilutions from 10-1 to 10-4 were made and $100 \mu \mathrm{L}$ of each dilution were plated on to Dichloran Rose Bengal Chloramphenicol agar (DRBC). DRBC plates were incubated at $25^{\circ} \mathrm{C}$ in darkness for 2 days. Afterwards the colonies were counted. The number of viable conidia (N) was calculated using the sum of colonies counted (C) in two consecutive dilutions, considering the number of plates counted at the first (n1) and second dilution (n2), taking into account the volume (V) dispensed to each plate and the dilution from which first count was obtained (d) (Eqn 1). Only Petri dishes with 15-150 colony-forming units (CFUs) were considered and the limit of detection of the whole procedure was $104 \mathrm{CFU}$.

Data analysis

As an equal number of conidia were irradiated for all isolates across the experiment $(5 \times 106$ conidia in each membrane), analysis of variance (ANOVA) was applied directly to log CFU data in order to determine the effect of species, sections, irradiation treatment, time and their interactions on conidial survival. In addition, ANOVA considered only data from species isolated from both regions (A. ochraceus, A. flavus, A. carbonarius and A. tubingensis) in order to evaluate the influence of geographical origin on conidia survival. Subsequently, significant effects were analysed by Tukey's honestly significant different test (HSD). Significance was defined as $P<0.05$.

\section{RESULTS}

Both types of radiation (UV-A and UV-B) caused significant effects on conidial survival compared to non-irradiated conidia, with a significant effect of the interaction between irradiation treatment and Aspergillus section studied and time of exposure $(P<0.001)$ (Table 2).

Some of the species studied in this work were isolated from two different regions (Table 1). Common irradiance values measured in the northeast are lower than values measured in the south. Nevertheless, no significant differences $(P>0.05)$ in the response to irradiation (UV-A or UV-B) were found as a result of the different origin of isolation. 
In general, a decrease in viability of conidia was observed over time for all isolates tested (Fig. 3). Species from the section Circumdati showed the greatest loss of conidial viability, both in UV-irradiated and control treatments; moreover, earlier ( 5 days) significant differences in viability due to UV radiation were observed in this section. Aspergillus sections Nigri and Flavi showed reduced viability after 10-15 days, although the relative decrease in viability after 15 days was less than 2 log cycles for all sections.

Mean viability ( $n=6$ ) of UV-exposed Aspergillus conidia over time (expressed as log CFU counts in DRBC plates). Error bars indicate standard deviation. Letters indicate homogeneous groups within time/irradiation treatments (Tukey HSD, $\mathrm{P}<0.05$ ).

Furthermore, data were analysed separately for each Aspergillus section in order to establish significant differences among species (Table 3). Within section Flavi, A. parasiticus was significantly more affected than A. flavus; similarly within section Nigri A. tubingensis was more affected than $A$. carbonarius but only when they were irradiated under UV-B, and no significant differences were observed within section Circumdati (Fig. 4).

The effect of UV-A and UV-B was not compared as both radiations were applied at different levels of intensity; however, as comparable levels of survival were observed and UV-B was applied at a lower irradiance, it is clear that UV-B produces more deleterious effects owing to its shorter wavelength.

\section{DISCUSSION}

Spain is one of the European countries which recieves higher amount of radiation but also the country that shows the greatest contrast and radiative gradients and complexity in the distribution of radiative energy.39 Values used in this study were based on mean values of. UV-A and UV-B global (direct and diffused) radiation measured in Seville, since this city has one of the highest intensities of radiation and number of hours of exposure values in Spain. In this work, the effect of UV-A ( $365 \mathrm{~nm})$ and UV-B $(312 \mathrm{~nm})$ radiation on mycotoxigenic fungal conidia survival, which are frequently isolated from crops, has been studied.

In this study conidia were dislodged on to membranes, and no source of water or nutrients was available. Moreover, light is a very important signal for fungi: it influences many different physiological responses such as pigmentation, sexual development, asexual conidiation, the circadian clock and secondary metabolism.40 For this reason, the experimental design consisted of alternating periods of dark and white light with UV radiation exposure included in the light periods, whereas this approach was not used in previous experiments where only UV light was tested.23, 24

Some authors have suggested that conidia pigmentation could represent an important protection against UV radiation.24, 30, 32, 41-44 Three differently coloured conidia of Aspergillus were tested in our experiment: yellow, green and black, belonging to sections Circumdati, Flavi and Nigri, respectively. Undoubtedly, conidia belonging to section Circumdati, with the lightest pigmentation, showed greater loss of viability, in both irradiated and nonirradiated treatments. Nevertheless, at the 5 th day, when no significant differences compared to the first day were observed in the controls, only significant differences due to irradiation 
were noticeable in section Circumdati under UV-A and section Circumdati and Flavi under UV$B$. The photo-protective potential under UV-C radiation of fungal pigments of three A. niger isolates possessing the same genetic background, but differing in their degree of pigmentation, have been studied recently by Esbelin et al.45 The authors reported that spores of A. niger with fawn and white pigmentation were more sensitive to continuous UV-C radiation than the wild-type A. niger isolate, with dark pigmentation. Dominance of dark-coloured microfungi is characteristic for almost all mycologically studied desert soils.46-48 Therefore, dark-coloured spores could confer more protection against UV-B radiation. In fact, this provides a logical explanation for the high number of black aspergilli on grapes subjected to prolonged sun exposure in countries with high UV irradiance, such as Spain, Italy and Greece.34, 49, 50

However, not only differences were found between sections, but also interspecific differences in conidial survival were found within Aspergillus sections Flavi and Nigri, showing that other characteristics could give protection to the conidia. Physical characteristics like the projected surface area-to-volume ratio (SAV) of spores or wall thickness have also been emphasized as responsible for conidial survival to radiation.24, 43, $44 \mathrm{In}$ fact, the projected SAV of spores is an important factor on UV sensitivity, as the lower sensitivity of spores was related to lower SAV values.24 The spores of Aspergillus species tested are spherical, and therefore lower SAV corresponds to bigger radius. Simões et al.51 described the structural diversity of spores of black aspergilli. Interestingly, A. carbonarius showed higher diameters $(7.658 \mu \mathrm{m})$ among the section Nigri, compared to other species like A. tubingensis $(3.972 \mu \mathrm{m})$ or A. niger (3.340 $\mu \mathrm{m})$. This could be the cause of significant differences between these species when irradiated with UV-B. Similarly, A. carbonarius was significantly more resistant than A. niger when it was irradiated for a short time under UV-C.41, 44 The authors also suggested that the resistance of A. carbonarius was due to the thicker conidial wall.

Focusing on UV-A, we found a relevant mortality of conidia due to exposure to $1.7 \mathrm{~mW} \mathrm{~cm}-2$ $(1836 \mathrm{~kJ} \mathrm{~m}-2)$ around the 5 th day on section Circumdati and the 10th day on Aspergillus sections Flavi and Nigri ( $3672 \mathrm{~kJ} \mathrm{~m}-2$ ). Twice the exposure time (12 $\mathrm{h} \mathrm{d}-1$ ) but lower irradiance $0.60-1.250 \mathrm{~mW} \mathrm{~cm}-2(43.2-540 \mathrm{~kJ} \mathrm{~m}-2 \mathrm{~d}-1)$ during one day did not cause any significant difference to germination percentage of sporangia of Bremia lactucae compared to dark incubation. 52 Shorter exposure times ( $3 \mathrm{~h} \mathrm{~d}-1)$ but under higher irradiance $(3.056-5.556 \mathrm{~mW}$ $\mathrm{cm}-2$ ) for 16 days (330-600 kJ m-2 d-1) caused different effects on germination depending on the species tested:24 it was enhanced in Penicillium purpurogenum, but reduced in Cladosporium cladosporoides.

Under UV-B radiation ( $0.1 \mathrm{~mW} \mathrm{~cm}-2$ for $6 \mathrm{~h} \mathrm{~d}-1,21.6 \mathrm{~kJ} \mathrm{~m}-2 \mathrm{~d}-1)$, a significant reduction was also observed on conidia viability around the 5th day on Aspergillus sections Circumdati and Flavi and the 10th day on Nigri. As for UV-A radiation, irradiation for 16 days at $<0.001-0.019$ $\mathrm{mW} \mathrm{cm}-2$ for $3 \mathrm{~h} \mathrm{~d}-1(0-2.1 \mathrm{~kJ} \mathrm{~m}-2 \mathrm{~d}-1)$ led to divergent effects depending on the species.24 Exposure of $B$. lactucae to doses of 0.150 and $0.700 \mathrm{~mW} \mathrm{~cm}-2$ in a range from 2 to $12 \mathrm{~h} \mathrm{(10.8-}$ $302.4 \mathrm{~kJ} \mathrm{~m}-2 \mathrm{~d}-1) 52$ resulted in highly reduced germination (71-100\%) compared to white light and darkness.

Field studies with sunlight exposure have shown greater conidia mortality than laboratory works27 for Alternaria solani (20\%), Uromyces phaseoli (40\%), Peronospora tabacina (93\%) 
and Venturia inequalis (95\%).22, 27, 36, 53 Exposure to direct sunlight showed a higher reduction in the viability of $A$. carbonarius conidia supported on filter membranes after $\sim 1$ week than in our case, although a small part of this decrease ( 15\%) was attributable to the wind, which could have blown some spores from the filter membranes.36 Similarly, no disease was observed in carnation inoculated with Fusarium wilt grown under direct solar radiation, whereas severe disease was observed in plants under $85 \%$ shade cover.53 The effect of solar irradiance in the field cannot be assessed independently of other physical variables, especially temperature 22 or protection by the infected host tissue. 27 For instance, spores on bunches could be somewhat shielded from sunlight, depending on the bunch and canopy architecture.36

Duguay and Klironomos41 suggested that despite spores being able to survive under certain condition, this does not imply that the resulting hyphae have the same advantages. GarcíaCela37 studied the effect of UV radiation on conidia deposited on culture medium, which can provide both nutrients and protection. Again UV-A and UV-B reduced germination and mycelial growth of the species tested; however, $A$. carbonarius was the most tolerant to UV radiation. Also, UV radiation reduced the mycotoxin production by $A$. carbonarius and $A$. parasiticus and interestingly affected the distribution of AFs, the ratios of the different AFs (AFB1, AFB2, AFG1 and AFG2) being different when A. parasticus colonies grew under UV-B.

Additionally, the species studied in this work were isolated from two different regions; however, no different sensitivity to UV was observed due to the origin of isolation. By contrast, previous works with Aspergillus species showed slightly different ecological profiles due to the origin of isolation.6, 54

\section{CONCLUSION}

The overall spore inoculum present in the field may decrease as a consequence of UV increase, as conidia mortality was observed in all species tested. Moreover, an increase in UV radiation may unbalance the surviving spore species present in vineyards, possibly favouring in the future an even higher predominance of black aspergilli.

\section{ACKNOWLEDGEMENTS}

The authors are grateful to the Spanish Government (AGL2010-22182-C04-01) and Commissioner for Universities and Research, Department of Innovation and Business of the Catalonia Government (AGAUR), for funding this research.

\section{REFERENCES}

1 Baquião AC, Zorzete P, Reis TA, Assunção E, Vergueiro S and Correa B, Mycoflora and mycotoxins in field samples of Brazil nuts. Food Control 28(2):224-229 (2012).

2 Copetti MV, lamanaka BT, Frisvad JC, Pereira JL and Taniwaki MH, Mycobiota of cocoa: from farm to chocolate. Food Microbiol 28(8):1499-1504 (2011). 
3 Da Silveira Campos R, Freitas-Silva O, Da Cunha FQ, De Lourdes Mendes De Souza M and De Freitas SC, Mycotoxigenic fungi and ochratoxin a in coffee fruits with prolonged stay on the tree and on the soil in the Brazilian Cerrado. Coffee Sci 4(2):136-148 (2009).

4 Denizel T, Jarvis B and Rolfe EJ, A field survey of pistachio (Pistacia vera) nut production and storage in Turkey with particular reference to aflatoxin contamination. J Sci Food Agric 27(11):1021-1026 (1976).

5 Freire F, Kozakiewicz Z and Paterson R, Mycoflora and mycotoxins in Brazilian black pepper, white pepper and Brazil nuts. Mycopathologia 149(1):13-19 (2000).

6 Giorni P, Magan N, Pietri A, Bertuzzi T and Battilani P, Studies on Aspergillus section Flavi isolated from maize in northern Italy. Int J Food Microbiol 113(3):330-338 (2007).

7 Heperkan D, Aran N and Ayfer M, Mycoflora and aflatoxin contamination in shelled pistachio nuts. J Sci Food Agric 66(3):273-278 (1994).

8 Makun HA, Dutton MF, Njobeh PB, Phoku JZ and Yah CS, Incidence, phylogeny and mycotoxigenic potentials of fungi isolated from rice in Niger State, Nigeria. J Food Saf 31(3):334-349 (2011).

9 Özer N, Koç M and Der B, The sensitivity of Aspergillus niger and Fusarium oxysporum f. sp. cepae to fungistasis in onion-growing soils. J Plant Pathol 91(2):401-410 (2009).

10 Riba A, Mokrane S, Mathieu F, Lebrihi A and Sabaou N, Mycoflora and ochratoxin A producing strains of Aspergillus in Algerian wheat. Int J Food Microbiol 122(1-2):85-92 (2008).

11 Sweany RR, Damann KE Jr and Kaller MD, Comparison of soil and corn kernel Aspergillus flavus populations: evidence for niche specialization. Phytopathology 101(8):952-959 (2011).

12 Zorzete P, Reis TA, Felício JD, Baquião AC, Makimoto P and Corrêa B, Fungi, mycotoxins and phytoalexin in peanut varieties, during plant growth in the field. Food Chem 129(3):957964 (2011).

13 Perrone G, Susca A, Cozzi G, Ehrlich K, Varga J, Frisvad JC et al., Biodiversity of Aspergillus species in some important agricultural products. Stud Mycol 59:53-66 (2007).

14 IPCC, Climate Change 2013: The Physical Science Basis. [Online]. IPCC Working Group I Contribution to AR5 (2013). Available: http://www.climatechange2013.org/ [23 July 2015].

15 Miraglia M, Marvin HJP, Kleter GA, Battilani P, Brera C, Coni E et al., Climate change and food safety: an emerging issue with special focus on Europe. Food Chem Toxicol 47(5):10091021 (2009).

16 Magan N, Medina A and Aldred D, Possible climate-change effects on mycotoxin contamination of food crops pre- and postharvest. Plant Pathol 60(1):150-163 (2011). 
17 Paterson RRM and Lima N, Further mycotoxin effects from climate change. Food Res Int 44(9):2555-2566 (2011).

18 Paterson RRM and Lima N, How will climate change affect mycotoxins in food? Food Res Int 43(7):1902-1914 (2010.

19 Tirado MC, Clarke R, Jaykus LA, McQuatters-Gollop A and Frank JM, Climate change and food safety: a review. Food Res Int 43(7):1745-1765 (2010).

20 Wu F, Bhatnagar D, Bui-Klimke T, Carbone I, Hellmich R, Munkvold G et al., Climate change impacts on mycotoxin risks in US maize. World Mycotoxin J 4(1):79-93 (2010).

21 WMO, The Global Climate 2001-2010: A Decade of Climate Extremes. Summary report. [Online]. World Meteorological Organization. Available: http://library.wmo.int/pmb_ged/wmo_1119_en.pdf [23 July 2015].

22 Aylor DE and Sanogo S, Germinability of Venturia inaequalis conidia exposed to sunlight. Phytopathology 87(6): 628-633 (1997).

23 Fourtouni A, Manetas $\mathrm{Y}$ and, Christias C, Effects of UV-B radiation on growth, pigmentation, and spore production in the phytopathogenic fungus Alternaria solani. Can J Bot 76(12):20932099 (1998).

24 Moody SA, Newsham KK, Ayres PG and Paul ND, Variation in the responses of litter and phylloplane fungi to UV-B radiation (290-315 nm). Mycol Res 103(11):1469-1477 (1999).

25 Nicot PC, Mermier M, Vaissière BE and Lagier J, Differential spore production by Botrytis cinerea on agar medium and plant tissue under near-ultraviolet light-absorbing polyethylene film. Plant Dis 80(5):555-558 (1996).

26 Osman M, Mohamed YA, el-Sayed MA and Abo-Zeid A, Effect of UV-irradiation on some aspects of metabolic activities in Aspergillus flavus and Penicillium notatum. Microbios 56(227):79-87 (1988).

27 Rotem J, Wooding B and Aylor DE, The role of solar radiation, especially ultraviolet, in the mortality of fungal spores. Phytopathology 75:510-514 (1985).

28 UNEP, Scientific Assessment of Ozone Depletion: 2010. [Online]. World Meteorological Organization Global Ozone Research and Monitoring Project: Report No. 52 (2010) Available: http://www.esrl.noaa.gov/csd/assessments/ozone/2010/chapters/chapter2.pdf [23 July 2015].

29 UNEP, Environmental Effects of Ozone Depletion: 2002 Assessment. United Nations Environment Programme, Nairobi.

30 Grishkan I, Beharav A, Kirzhner V and Nevo E, Adaptive spatiotemporal distribution of soil microfungi in 'Evolution Canyon' III, Nahal Shaharut, extreme southern Negev Desert, Israel. Biol J Linn Soc 90(2):263-277 (2007). 
31 Grishkan I, Nevo E, Wasser SP and Beharav A, Adaptive spatiotemporal distribution of soil microfungi in 'Evolution Canyon' II, Lower Nahal Keziv, western Upper Galilee, Israel. Biol J Linn Soc 78(4):527-539 (2003).

32 Ulevičius V, Pečiulytè D, Lugauskas A and Andriejauskienè J, Field study on changes in viability of airborne fungal propagules exposed to UV radiation. Environ Toxicol 19(4):437-441 (2004).

33 Iberian Climate Atlas, Air temperature and precipitation (1971-2000). [Online]. Agencia Estatal de Meteorología Ministerio de Medio Ambiente y Medio Rural y Marino, Instituto de Meteorologia de Portugal. Available:

http://www.aemet.es/documentos/es/serviciosclimaticos/datosclimatologicos/atlas_radiacion _solar/atlas_de_radiacion_24042012.pdf [30 July 2015]

34 García-Cela E, Crespo-Sempere, A, Gil-Serna J, Porqueres A and Marin S, Fungal diversity, incidence and mycotoxin contamination in grapes from two agro-climatic Spanish regions with emphasis on Aspergillus species. J Sci Food Agric 95(8): 1716-1729 (2014).

35 Delfini C. 1982. Tecnica di microbiologia enological. Luigi Scalpi, Rome.

36 Leong S-I. L, Hocking AD and Scott ES, Survival and growth of Aspergillus carbonarius on wine grapes before harvest. Int J Food Microbiol 111:S83-87 (2006).

37 García-Cela E, Marin S, Sanchis V, Crespo-Sempere A and Ramos AJ, Effect of ultraviolet radiation $A$ and $B$ on growth and mycotoxin production by Aspergillus carbonarius and Aspergillus parasiticus in grape and pistachio media. Fungal Biol 119(1):67-78 (2015).

38 Ortega Resinas M, Martín Gutiérrez FJ and Camacho F, Medidas de la radiación solar ultravioleta en Sevilla. Actas Dermosifiliogr 92:271-275 (2001).

39 AEMET 2012, Atlas de radiación solar en España utilizando datos del SAF de clima de EUMETSAT [Online]. Agencia Estatal de Meteorología; Available:

http://www.aemet.es/documentos/es/serviciosclimaticos/datosclimatologicos/atlas_radiacion _solar/atlas_de_radiacion_24042012.pdf [23 July 2015].

40 Bayram Ö, Braus GH, Fischer R and Rodriguez-Romero J, Spotlight on Aspergillus nidulans photosensory systems. Fungal Genet Biol 47(11): 900-908 (2010).

41 Duguay KJ and Klironomos JN, Direct and indirect effects of enhanced UV-B radiation on the decomposing and competitive abilities of saprobic fungi. Appl Soil Ecol 14(2):157-164 (2000).

42 Osman M, Elsayed MA, Mohamed YAH and Abo-Zeid AM, Effect of ultraviolet irradiation on germination and growth in Aspergillus flavus and Penicillium notatum. Mycol Res 92:293296 (1989).

43 Rotem J and Aust HJ, The effect of ultraviolet and solar radiation and temperature on survival of fungal propagules. J Phytopathol 133:76-84 (1991). 
44 Valero A, Begum M, Leong SL, Hocking AD, Ramos AJ, Sanchis V et al., Effect of germicidal UVC light on fungi isolated from grapes and raisins. Lett Ap pl Microbiol 45(3):238-243 (2007).

45 Esbelin J, Mallea S, Ram AFJ and Carlin F, Role of pigmentation in protecting Aspergillus niger conidiospores against pulsed light radiation. Photochem Photobiol 89(3):758-761 (2013).

46 Halwagy R, Moustafa AF and Kamel SM, Ecology of the soil mycoflora in the desert of Kuwait. J Arid Environ 5(2):109-125 (1982).

47 Mulder JL and El-Hendawy H, Microfungi under stress in Kuwait's coastal saline depressions. Kuwait J Sci Eng 26(1):155-171 (1999).

48 Ranzoni FV, Fungi isolated in culture from soils of the Sonoran desert. Mycologia 60(2):356-371 (1968).

49 Battilani P, Barbano C, Marin S, Sanchis V, Kozakiewicz Z and Magan N, Mapping of Aspergillus section Nigri in Southern Europe and Israel based on geostatistical analysis. Int J Food Microbiol 111:S72-82 (2006).

50 Tjamos SE, Antoniou PP and Tjamos EC, Aspergillus spp., distribution, population composition and ochratoxin A production in wine producing vineyards in Greece. Int J Food Microbiol 111:S61-66 (2006).

51 Simões MF, Santos C and Lima N, Structural diversity of Aspergillus (section Nigri) spores. Microsc Mycroanal 19:1151-1158 (2013).

$52 \mathrm{Wu} B M$, Subbarao KV and Van Bruggen AHC, Factors affecting the survival of Bremia lactucae sporangia deposited on lettuce leaves. Phytopathology 90:827-33 (2000).

53 Ben-Yephet $Y$ and Shtienberg D, Effects of solar radiation and temperature on Fusarium wilt in carnation. Phytopathology 84(12):1416-1421 (1994).

54 García-Cela E, Crespo-Sempere A, Ramos AJ, Sanchis V and Marin S. Ecophysiological characterization of Aspergillus carbonarius, Aspergillus tubingensis and Aspergillus niger isolated from grapes in Spanish vineyards. Int J Food Microbiol 173:89-98 (2014). 


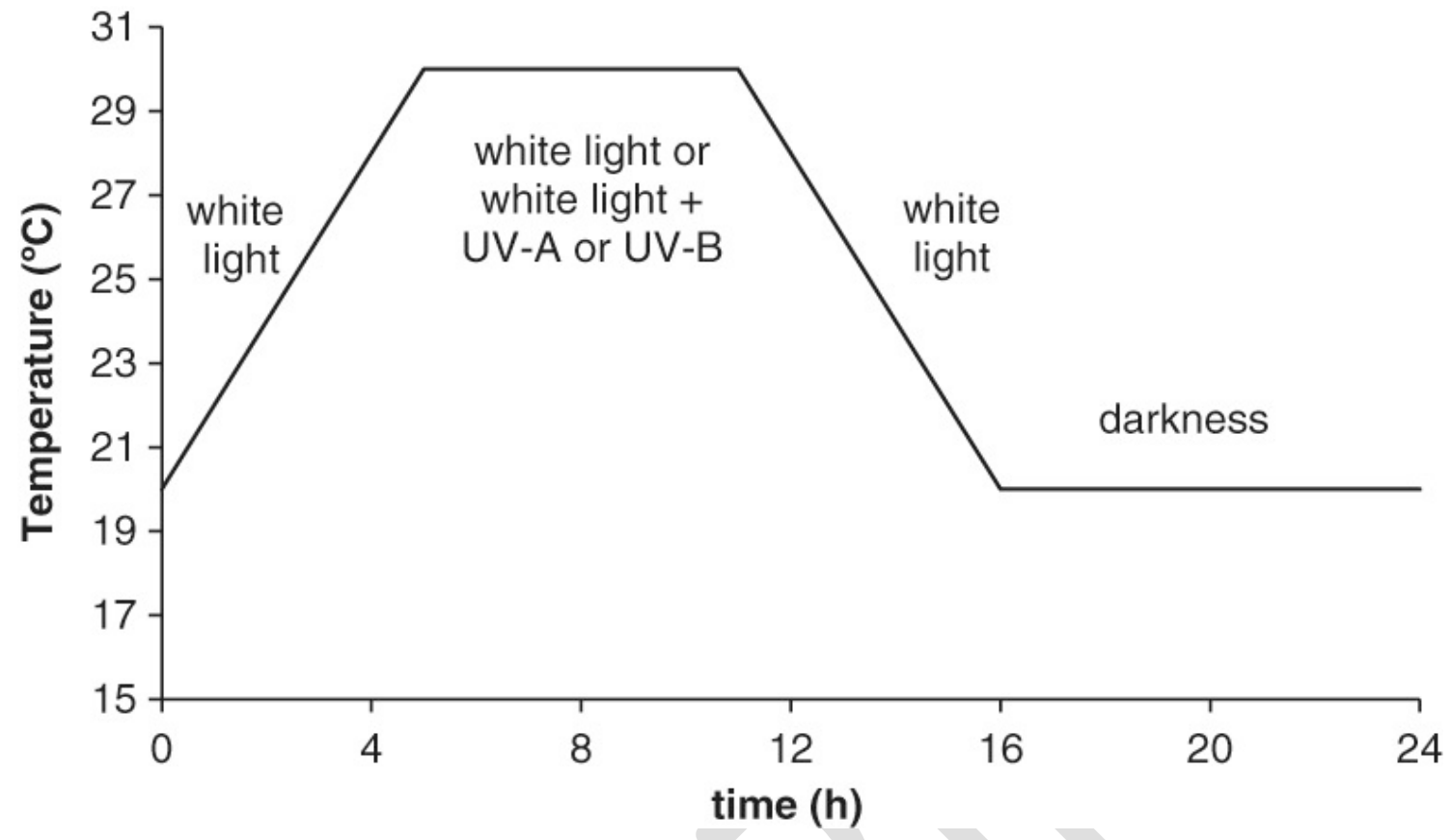

Figure 1

Daily light and temperature conditions for incubation of conidia on filter membranes. 

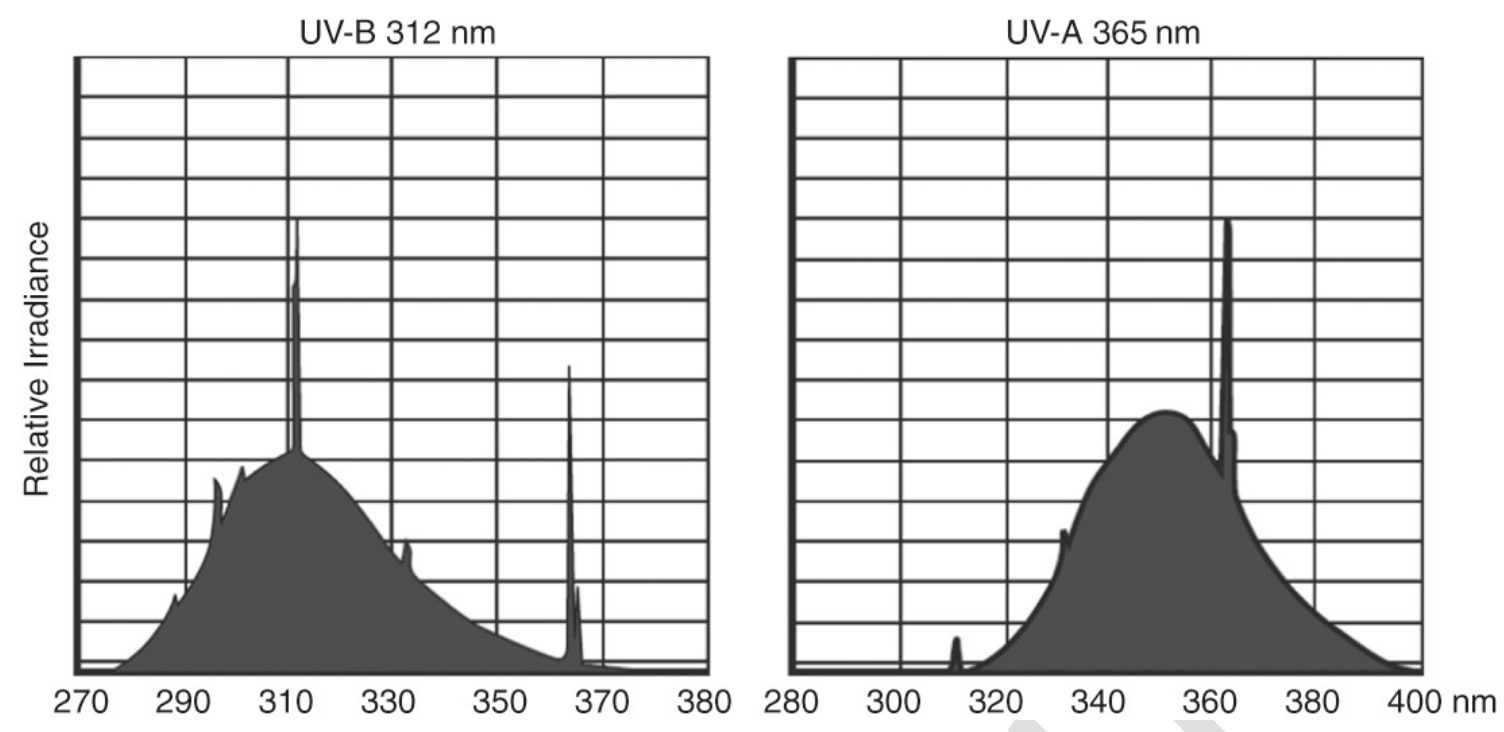

Figure 2

Spectral curves of UV tubes. 


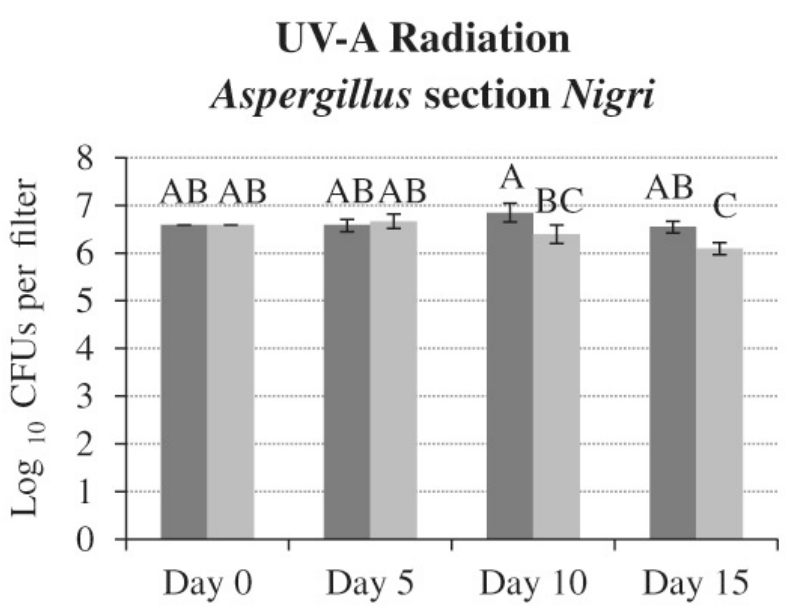

Aspergillus section Flavi

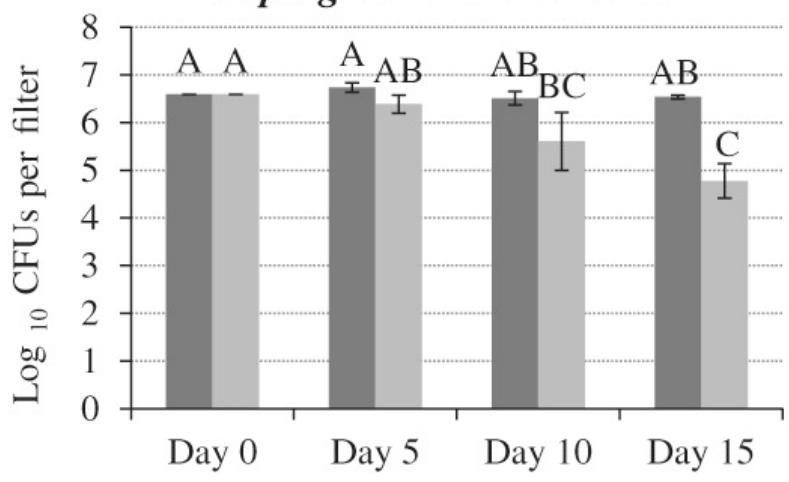

Aspergillus section Circumdati

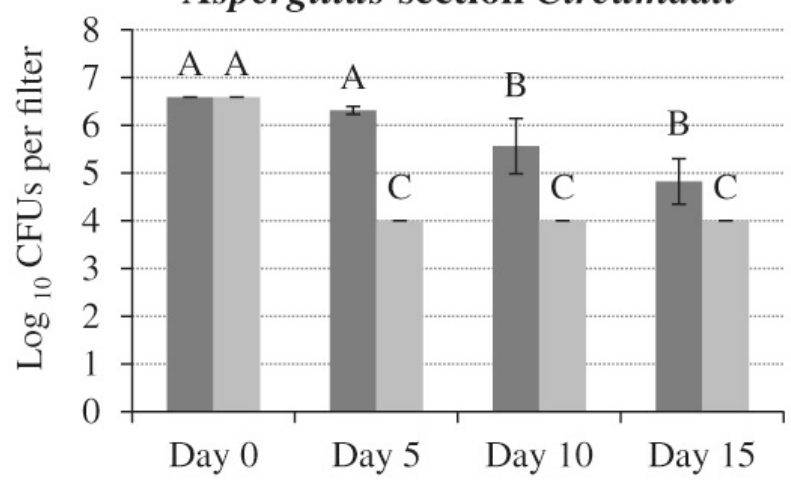

Figure 3

Mean viability ( $n=6$ ) of UV-exposed Aspergillus conidia over time (expressed as log CFU counts in DRBC plates). Error bars indicate standard deviation. Letters indicate homogeneous groups within time/irradiation treatments (Tukey HSD, P $<0.05$
UV-B Radiation Aspergillus section Nigri

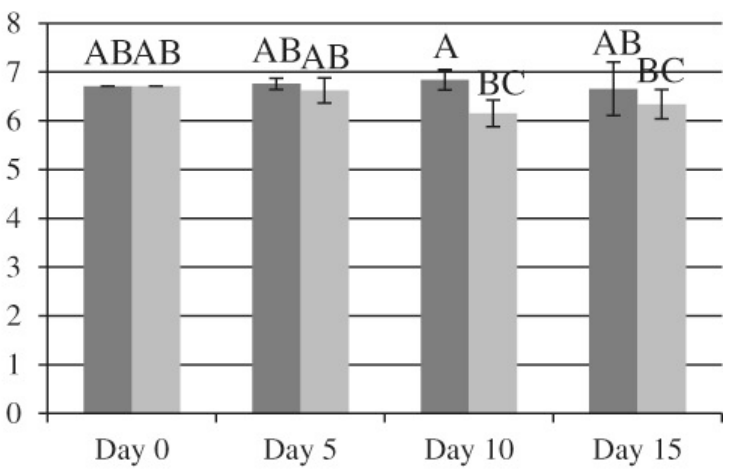

Aspergillus section Flavi

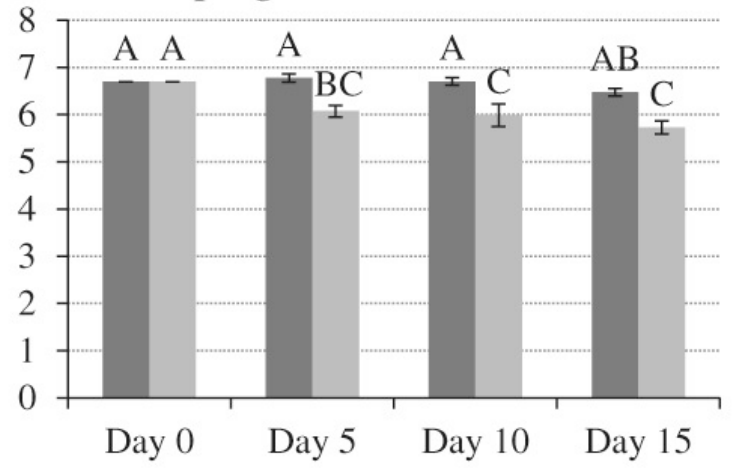

Aspergillus section Circumdati

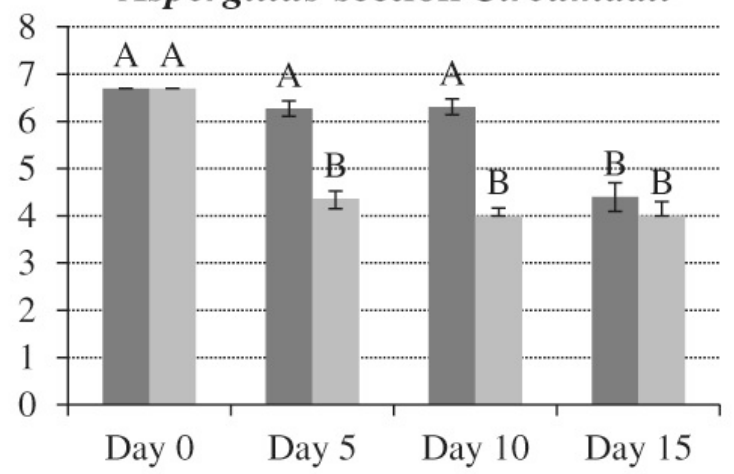

Irradiation 
UV-A Radiation

Aspergillus section Nigri

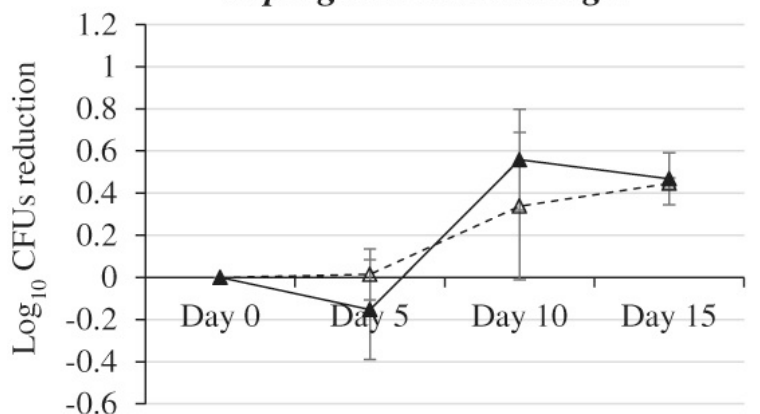

Aspergillus section Flavi

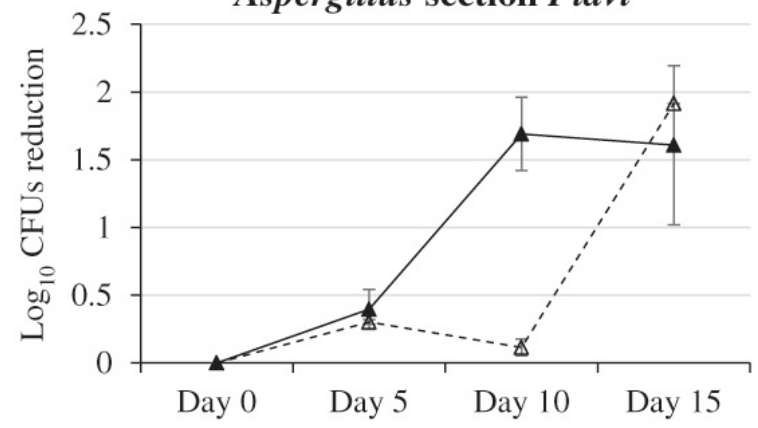

Aspergillus section Circumdati

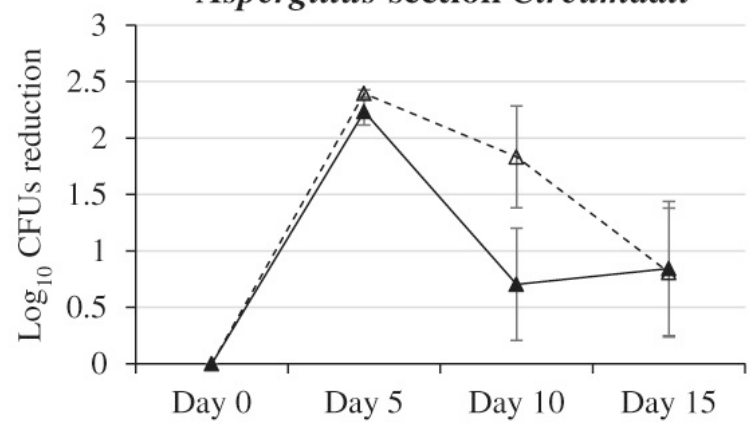

section Nigri

$\triangle \quad$ A. carbonarius

A. tubingensis section Flavi

$\triangle$ A. parasiticus

- A. flavus
UV-B Radiation

Aspergillus section Nigri

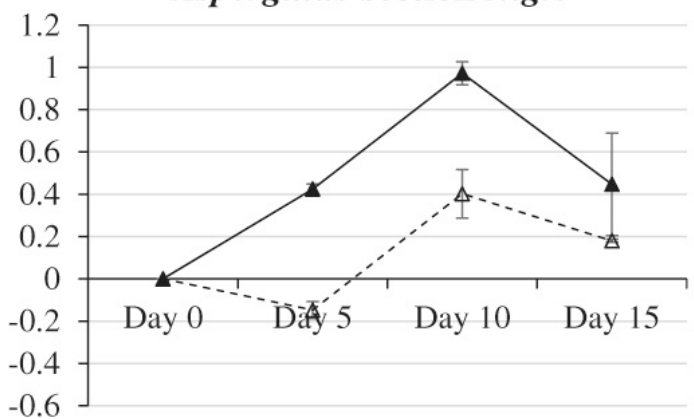

Aspergillus section Flavi

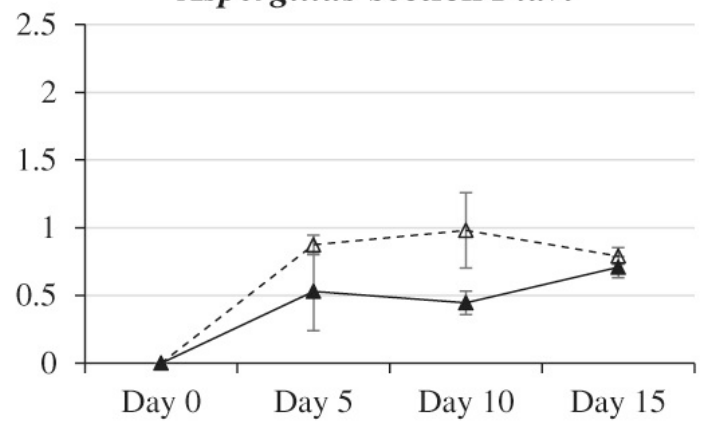

Aspergillus section Circumdati

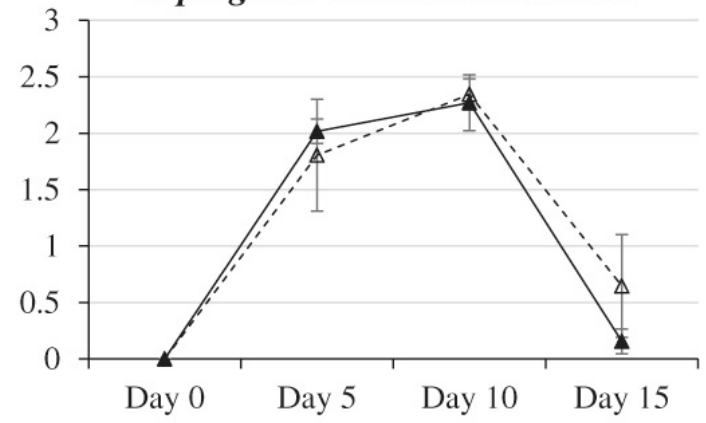

section Circumdati

$\triangle$ A. ochraceus

- A. westerdijkiae

Figure 4

Logarithmic reduction of conidial survival for each species due to the UV irradiation over time 
Table 1. Data on isolates used in the study

\section{Reference $^{\mathrm{a}}$ Section Species Origin in Spain Year}

AC14-UdLTA Circumdati A. westerdijkiae South 2012

AC18-UdLTA Circumdati A. westerdijkiae South 2012

AC7-UdLTA Circumdati A. ochraceus Northeast 2012

AC16-UdLTA Circumdati A. ochraceus South 2012

AF51-UdLTA Flavi A. flavus South 2012

AF34-UdLTA Flavi A. flavus Northeast 2012

AF41-UdLTA Flavi A. parasiticus Northeast 2012

AF16-UdLTA Flavi A. parasiticus Northeast 2012

311-UdLTA Nigri A. carbonarius South 2011

287-UdLTA Nigri A. carbonarius Northeast 2011

276-UdLTA Nigri A.tubingensis South 2011

68-UdLTA Nigri A. tubingensis Northeast 2011

${ }^{a}$ References are the codes of cultures held in the Food Technology Department Culture Collection of the University of Lleida. 
Table 2. ANOVA data for the effect of Aspergillus section, time of exposure, UV treatment and interactions among them on survival of conidia

\begin{tabular}{|c|c|c|c|c|c|}
\hline \multirow{2}{*}{ Source } & \multicolumn{3}{|c|}{ d.f. Sum of squares } & \multicolumn{2}{|c|}{ F-ratio } \\
\hline & d.t. & UV-A & UV-B & UV-A & UV-B \\
\hline Time & 3 & 40.45 & 29.94 & $46.86 * *$ & $76.01^{* *}$ \\
\hline Section & 2 & 62.80 & 57.81 & $109.12 * *$ & $220.16^{* *}$ \\
\hline Treatment & 1 & 22.73 & 20.93 & 78.99** & $159.39 * *$ \\
\hline Time $\times$ Section & 6 & 22.94 & 24.59 & $13.28 * *$ & $31.22 * *$ \\
\hline Time $\times$ Treatment & 3 & 7.75 & 10.36 & $8.97 * *$ & $26.3^{* *}$ \\
\hline Section $\times$ Treatment & & 6.48 & 6.39 & $11.25^{* *}$ & $24.34 * *$ \\
\hline
\end{tabular}


Table 3. ANOVA data for the effect of species, time, irradiation and their interactions on conidia survival within each Aspergillus section

\begin{tabular}{|c|c|c|c|c|c|c|}
\hline & Source & d.f. & $\begin{array}{l}\text { Sur } \\
\text { squ }\end{array}$ & $\begin{array}{l}\text { m of } \\
\text { lares }\end{array}$ & $F-1$ & ratio \\
\hline & & & UV-A & UV-B & UV-A & UV-B \\
\hline & Species & 1 & 0.01 & 0.09 & $\begin{array}{l}0.12 \\
\text { n.s. }\end{array}$ & 1.42 n.s. \\
\hline & Time & 3 & 1.34 & 0.66 & $5.52 *$ & $3.29 *$ \\
\hline & Irradiation & 1 & 0.70 & 1.30 & $8.63 *$ & $19.47 * *$ \\
\hline Aspergillus section Nigri & Species $\times$ Time & 3 & 0.01 & 0.09 & 0.05 & 0.46 n.s. \\
\hline & $\begin{array}{l}\text { Species } \times \\
\text { Irradiation }\end{array}$ & 1 & 0.00 & 0.50 & $\begin{array}{l}0.02 \\
\text { n.s. }\end{array}$ & $7.45 *$ \\
\hline & Time $\times$ Irradiation & 3 & 0.96 & 1.06 & $3.94 *$ & $5.3^{*}$ \\
\hline & Species & 1 & 1.67 & 0.60 & $5.99 *$ & $11.39 *$ \\
\hline & Time & 3 & 11.01 & 3.02 & $13.17 * *$ & $18.97 * *$ \\
\hline & Irradiation & 1 & 9.09 & 4.69 & $32.59 * *$ & $88.32 * *$ \\
\hline Aspergillus section Flavi & Species $\times$ Time & 3 & 3.17 & 0.41 & $3.79 *$ & 2.6 n.s. \\
\hline & $\begin{array}{l}\text { Species } \times \\
\text { Irradiation }\end{array}$ & 1 & 0.46 & 0.23 & $\begin{array}{l}1.67 \\
\text { n.s. }\end{array}$ & $4.35^{*}$ \\
\hline & Time $\times$ Irradiation & 3 & 7.09 & 1.57 & $8.47 * *$ & $9.84 * *$ \\
\hline & Species & 1 & 0.39 & 0.04 & $\begin{array}{l}1.51 \\
\text { n.s. }\end{array}$ & 0.32 n.s. \\
\hline & Tim & 3 & 51.03 & 51.28 & $65.47 * *$ & $124.21^{* *}$ \\
\hline & Irradiation & 1 & 19.42 & 21.33 & $74.76^{* *}$ & $155.02^{* *}$ \\
\hline Circumdati & Species $\times$ Time & 3 & 0.91 & 0.22 & $\begin{array}{l}1.17 \\
\text { n.s. }\end{array}$ & 0.54 n.s. \\
\hline & $\begin{array}{l}\text { Species } \times \\
\text { Irradiation }\end{array}$ & 1 & 0.39 & 0.03 & $\begin{array}{l}1.51 \\
\text { n.s. }\end{array}$ & 0.23 n.s. \\
\hline & Time $\times$ Irradiation & 3 & 11.15 & 15.22 & $14.31^{* *}$ & $36.86 * *$ \\
\hline
\end{tabular}

